(2) OPEN ACCESS

\section{Manage wisely: poly (ADP-ribose) polymerase inhibitor (PARPi) treatment and adverse events}

Ainhoa Madariaga (D) , ${ }^{1}$ Valerie Bowering, ${ }^{1}$ Soha Ahrari, ${ }^{2}$ Amit M Oza, ${ }^{1}$ Stephanie Lheureux ${ }^{1}$

\begin{abstract}
${ }^{1}$ Medical Oncology \& Hematology, Princess Margaret Hospital Cancer Centre, Toronto, Ontario, Canada

${ }^{2}$ Pharmacy, Princess Margaret Hospital Cancer Centre, Toronto, Ontario, Canada
\end{abstract}

\section{Correspondence to} Stephanie Lheureux, Medical Oncology \& Hematology, Princess Margaret Hospital Cancer Centre, Toronto, ON M5G 2C, Canada; Stephanie. Lheureux@uhn.ca

Received 3 February 2020 Revised 25 February 2020 Accepted 27 February 2020 Published Online First 9 April 2020
D) Check for updates

(C) IGCS and ESGO 2020. Re-use permitted under CC BY-NC. No commercial re-use. Published by BMJ.

To cite: Madariaga A,
Bowering V, Ahrari S,
et al. Int J Gynecol Cancer
2020;30:903-915.

\section{ABSTRACT}

Poly (ADP-ribose) polymerase (PARP) inhibitors (PARPi) have transformed the treatment landscape in front-line and recurrent high-grade serous ovarian cancer. Maintenance strategies with PARPi have been assessed in randomized phase III trials in ovarian cancer; switch maintenance in the case of olaparib, niraparib, and rucaparib; and concurrent followed by continuation maintenance with veliparib. These studies have shown progression-free survival advantage with PARPi maintenance, with no major adverse changes in the quality of life; however, overall survival data remain immature to date. PARPi have also been incorporated in clinical practice as a single-agent treatment strategy in high-grade serous ovarian cancer, mainly in women who harbor alterations in the BRCA1/2 genes or have alterations in the homologous recombination deficiency (HRD) pathway. Contemporary studies are looking into potentially synergistic combination strategies with antiangiogenics and immune checkpoint inhibitors, among others. The expansion of PARPi treatment has not been limited to ovarian cancer; talazoparib is licensed in patients with HER2-negative breast cancer with germline BRCA mutations (BRCAm), and front-line olaparib maintenance in patients with pancreatic cancer with germline BRCAm. Numerous studies assessing PARPi either in monotherapy or in combination with other agents are ongoing in multiple tumors, including prostate, endometrial, brain, and gastric cancers. Many patients are being treated with PARPi, some for prolonged periods of time. As a result, a thorough knowledge of the potential short- and long-term adverse events and their management is warranted to improve patient safety, treatment efficacy, and towards maintaining an appropriate dose intensity.

\section{INTRODUCTION}

Ovarian cancer is the most lethal gynecologic malignancy in developed countries. ${ }^{1}$ Approximately $90 \%$ are epithelial, and can be divided within five subtypes: high- and low-grade serous, endometrioid, clear cell, and mucinous carcinoma. ${ }^{2}{ }^{3}$ of these, highgrade serous ovarian carcinoma remains the most common subtype $(>70 \%)$. Germline alterations in breast cancer 1 (BRCA1) and breast cancer 2 (BRCA2) genes are identified in $14 \%-18 \%$ of patients with high-grade serous ovarian cancer, while $\sim 3 \%$ harbor somatic BRCA mutations (BRCAm) or inactivations due to methylation. ${ }^{4}$ More broadly, homologous recombination deficiency (HRD), involved in repair of
DNA damage and replication, are detected in approximately half of the patients with high-grade serous ovarian cancer. ${ }^{5}$ Major recent improvement in the treatment landscape has been achieved with maintenance poly (ADP-ribose) polymerase (PARP) inhibitor (PARPi) therapy. ${ }^{6}$ Ovarian cancers with BRCAm or HRD alterations are particularly sensitive to PARPi because of the accumulation of unrepaired DNA breaks that lead to cellular death. ${ }^{7}$ PARPi maintenance treatments have provided an enhancement of disease-free and progression-free survival, with no significant changes in the health-related quality of life (QoL). ${ }^{6}$ Given that PARPi are administered orally, they are sometimes perceived as well-tolerated drugs by clinicians; however, experienced management of toxicity is warranted, particularly in this context of chronic use. Adverse events related to PARPi treatment and their management will be discussed in this review. For the purpose of this review we will focus on studies assessing PARPi as a single agent, either as a monotherapy treatment or maintenance strategy in ovarian cancer. Similar approaches are used in PARPi adverse event management in other solid tumors, including breast, pancreatic, and prostate cancer. ${ }^{89}$

\section{PARP Inhibitors: Mechanism of Action, Dosing and Pharmacokinetics}

PARP enzymes, particularly PARP1 and PARP2, are essential in the repair of DNA single-strand breaks. ${ }^{7}$ The inhibition of PARP enzymes leads to persistent single-strand breaks, which cause accumulation of double-strand breaks during DNA replication and ultimately leads to cell cycle arrest or cellular death. ${ }^{7}$ Cancer cells with BRCAm or HRD, involved in double-strand break repair, are particularly sensitive to PARPi treatment. ${ }^{7}$ This corresponds to the concept of 'synthetic sickness' - synergistic loss of function in two repair pathways leads to cell death but a loss of function of one pathway alone does not. ${ }^{10}$ In the setting of BRCAm, loss of function related to the mutation coupled with synthetically inhibiting PARP leads to cellular lethality. Other mechanisms of PARPi include regulation of the non-homologous end-joining pathway, as well as trapping of inactive PARP enzymes at the level of single-strand breaks, preventing their repair. ${ }^{11}$ 


\section{Review}

The pharmacokinetics of PARPi, including metabolism and drug interactions vary from one agent to another and are summarized in Table $1 .{ }^{12-16}$ In general, PARPi can be administered with or without food. Seville oranges and grapefruit should be avoided in those patients taking olaparib, since they are CYP3A inhibitors, ${ }^{12}$ while rucaparib may increase the effects of caffeine. ${ }^{17}$

\section{PARP Inhibitor as Single Agent: Maintenance and Treatment Monotherapy}

First-line maintenance randomized trials have shown a robust disease-free survival/progression-free survival improvement with PARPi treatment in ovarian cancer; overall survival data remain immature to date. ${ }^{18-20}$ Two placebo-controlled phase III trials have assessed switch-maintenance PARPi treatment in patients that respond to front-line platinum; SOL01 (NCT01844986) assessed olaparib in patients with ovarian cancer harboring somatic and germline $B R C A m,{ }^{18}$ and PRIMA/ENGOT-Ov26 (NCT02655016) assessed niraparib in the overall population (non-restricted to BRCAm carriers). ${ }^{19}$ Contrary to these, the VELIA (NCT02470585) three-arm, placebo-controlled phase III trial assessed a concurrent followed by continuation-maintenance strategy with the incorporation of veliparib in combination with chemotherapy followed by maintenance veliparib (Figure 1). ${ }^{20}$ The latter has the effect that potentially a larger proportion of patients including ones who were not in partial or complete response after first-line therapy went on to receive maintenance therapy. Similarly, in platinum-sensitive recurrence, a randomized phase II trial, Study19 (NCT00753545), ${ }^{21}$ led the way to three subsequent randomized placebo-controlled phase III trials. SOL02/ENG0T-Ov21 (NCT01874353) assessing olaparib in somatic and germline BRCAm carriers, ${ }^{22}$ ENGOT-OV16/NOVA (NCT01847274), and ARIEL3 (NCT01968213) assessing niraparib and rucaparib maintenance in the overall population, respectively, have shown progression-free survival improvement in patients that responded to platinum treatment (Figure 1). ${ }^{23} 24$ In front-line maintenance, olaparib was administered for 2 years in patients that had complete response to initial therapy $;{ }^{18}$ however, front-line niraparib and PARPi in platinum-sensitive maintenance were continued until unacceptable toxicity or progression. ${ }^{1922-24}$ Long-term responders that remain on the drug for $>5$ years have been described. ${ }^{25}$ Table 2 summarizes the different selection criteria used in the phase III maintenance trials. ${ }^{18-20} 22-24$ For extended review regarding efficacy see Longo ${ }^{26}$ and Lheureux et al. ${ }^{27}$

PARPi have also been evaluated as monotherapy treatment in recurrent ovarian cancer mainly through non-randomized phase II clinical trials, showing relevant objective response rate and progression-free survival, mainly in BRCA/HRD-positive and platinum-sensitive patients. ${ }^{28-32}$ Olaparib monotherapy was assessed as part of a multi-tumor phase II trial in patients with $\geq 3$ prior lines of chemotherapy that were germline BRCAm carriers and either platinum-resistant or non-suitable for platinum. ${ }^{29}$ Niraparib monotherapy was assessed in a single-arm phase II trial in patients with $\geq 3$ prior lines of chemotherapy that were either BRCAm carriers (regardless of platinum sensitivity) or platinum-sensitive non-BRCA HRD patients. ${ }^{30}$ A phase I/II (in BRCAm) and phase II study (ARIEL2, overall population) assessed treatment with rucaparib monotherapy; ${ }^{31}{ }^{32}$ an integrated pooled analysis demonstrated efficacy in germline or somatic BRCAm carriers with $\geq 2$ lines of chemotherapy. ${ }^{33}$ ARIEL2 trial also demonstrated efficacy of rucaparib in the HRD and intention-to-treat population. ${ }^{31}$ The specific drug approvals by regulatory agencies are discussed below.

\section{PARP Inhibitors in Combination with Other Agents}

Several studies have evaluated the combination of PARPi with chemotherapy. A randomized phase II trial, STUDY41 (NCT01081951), assessed a continuation-maintenance of olaparib in patients with platinum-sensitive recurrence, with a progressionfree survival improvement in the combination arm. ${ }^{34}$ The trial was not designed to measure the contribution of each treatment, but the late separation of the progression-free survival curves suggested that the maintenance phase was the key contributor to the improvement. ${ }^{34}$ Similarly, front-line continuation-maintenance treatment with veliparib showed an improvement in progressionfree survival; however, no significant differences were seen when veliparib was administered in combination with chemotherapy (without maintenance) versus the placebo arm, ${ }^{20}$ and therefore by inference demonstrating that the benefit of veliparib in the concurrent/maintenance arm is driven mainly though post-platinum maintenance.

Contemporary studies are evaluating other potential synergistic combination strategies including anti-angiogenics, immunecheckpoint inhibitors, phosphoinositide 3-kinase/protein kinase B (PI3K/AKT) inhibitors, and cell cycle checkpoint inhibitors. Antiangiogenics being assessed in combination trials include bevacizumab, an anti-vascular endothelial growth factor monoclonal antibody, and cediranib, a vascular endothelial growth factor receptor and c-kit tyrosine kinase inhibitor. ${ }^{35}{ }^{36}$ In a phase III front-line maintenance clinical trial, PAOLA1/ENG0T-ov25 (NCT02477644), bevacizumab $(15 \mathrm{mg} / \mathrm{kg}$, every 3 weeks) and olaparib (300 mg, tablets twice daily) versus maintenance bevacizumab $(15 \mathrm{mg} / \mathrm{kg}$, every 3 weeks) and placebo was assessed, in patients with response to carboplatin-paclitaxel and bevacizumab. ${ }^{35}$ The study showed a significant progression-free survival improvement in the olaparib arm, but overall survival data remain immature. The incidence of serious adverse events was similar in both groups. In the recurrent setting, several randomized phase II studies have evaluated the role of PARPi treatment as monotherapy versus in combination with anti-angiogenics. Liu and colleagues assessed treatment with olaparib (400 mg, capsules twice daily) versus olaparib (200 mg, capsules twice daily) and cediranib ( $30 \mathrm{mg}$ once daily) in platinumsensitive recurrence. ${ }^{36}$ There was a significant progression-free survival improvement, with no changes in overall survival in the intention-to-treat population. In an exploratory subgroup analysis, patients that were germline BRCA wild-type seemed to potentially benefit more from this treatment, with progression-free survival and overall survival improvement only seen in that subgroup of patients. ${ }^{36}$ Nevertheless, grade $\geq 3$ adverse events were reported by $70 \%$ of patients in the combination arm, mainly hypertension, diarrhea, and fatigue. Our group assessed the combination of olaparib (300 mg, tablets twice daily) and cediranib (20 mg once daily) in a single-arm phase II study in patients having progressed to prior PARPi treatment, regardless of platinum sensitivity, and showed a signal of activity. ${ }^{37}$ Treatment-related grade $\geq 3$ adverse events were $38 \%$ in this case, mainly diarrhea, followed by anemia; the difference in drug dosing between the two studies might explain the numerical difference in adverse events' severity and frequency. Another phase II study in platinum-sensitive recurrence 


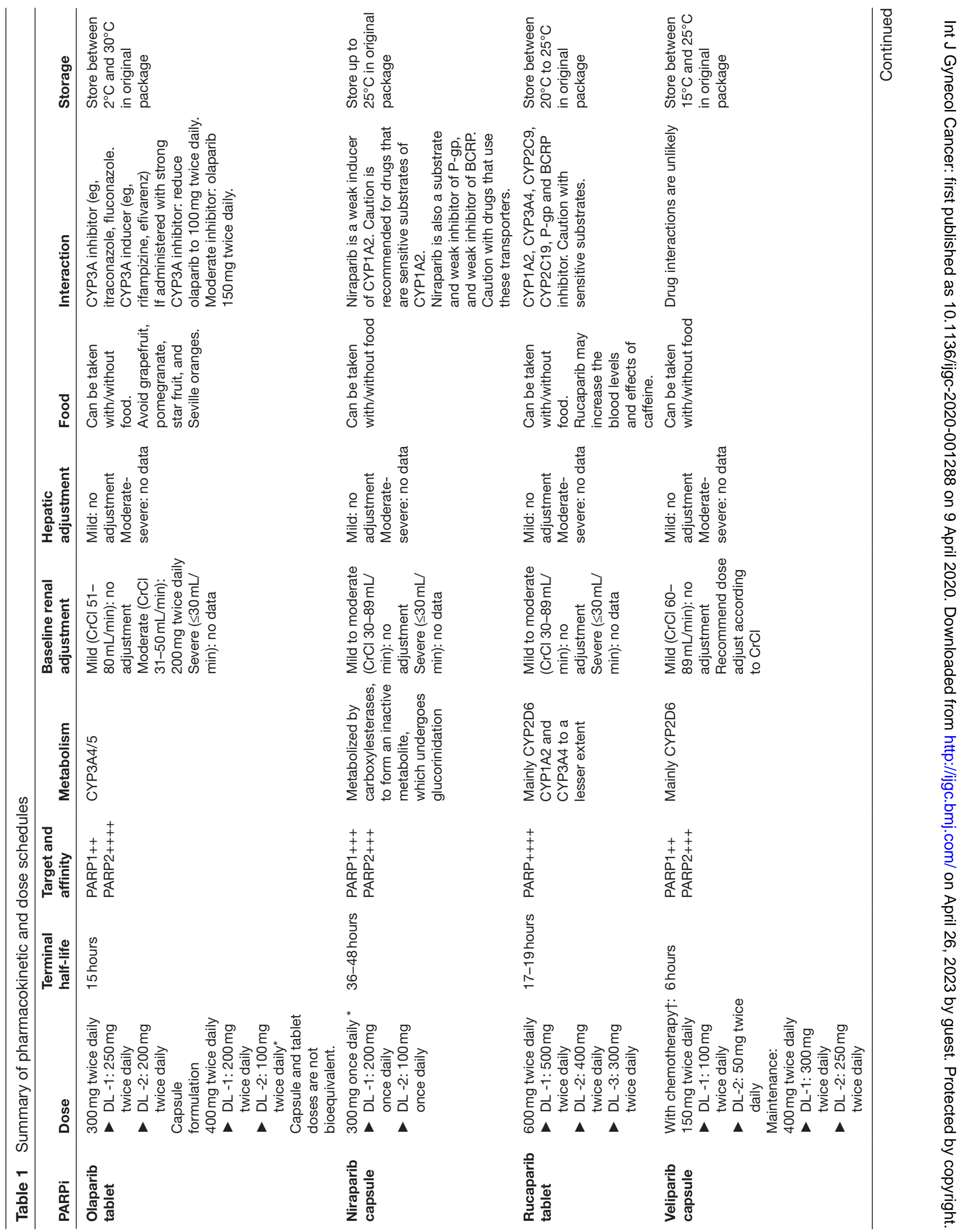


(patients with front-line bevacizumab and/or PARPi also included) assessed niraparib versus niraparib ( $300 \mathrm{mg}$, once daily) and bevacizumab (15 mg/kg, every 3 weeks) as a treatment strategy; showing a significant improvement in progression-free survival in the intention-to-treat population (irrespective of HRD), as well as in the pre-specified non-germline BRCAm carrier subgroup, but not in BRCAm carriers. ${ }^{38}$ Grade $\geq 3$ adverse events were more frequent in the combination arm ( $65 \%$ vs $45 \%)$, largely driven by more frequent hypertension; however, dose reductions were similar between arms and discontinuations numerically lower in the combination arm. ${ }^{38}$

Preliminary results from two multi-tumor early-phase trials have shown a signal of activity of the combination of PARPi with immunecheckpoint inhibitors, with overall response rates of $25 \%-72 \%{ }^{39}{ }^{40}$ Across both trials, the most common grade $\geq 3$ adverse events in the ovarian cancer cohort were anemia $(9 \%-21 \%)$, neutropenia $(3 \%-4 \%)$, and laboratory abnormalities (amylase and lipase elevation), suggesting that the combination may be tolerable. Clinical trials assessing the combination of chemotherapy, anti-angiogenics, PARPi, and immune-checkpoint inhibitors are ongoing in the front-line and recurrent settings (NCT03737643, NCT03522246, NCT03574779).

\section{MANAGEMENT OF ADVERSE EVENTS}

The PARPi adverse events can be associated with on- and offtarget effects. Many adverse events of PARPi treatment are class effects, meaning that all the drugs of the PARPi family are associated with these specific adverse events. ${ }^{41}$ However, it is important to recognize specific drug-to-drug differences, including non-class effect adverse events as well as different incidence of the class effect adverse events. A meta-analysis examining the differences in toxicity between olaparib, niraparib, and rucaparib showed that hematologic adverse events were significantly related to niraparib, abdominal pain to rucaparib, and diarrhea to olaparib. ${ }^{41}$ It is important to note that there is currently a recommendation to dose-adjust niraparib according to platelet level and weight at baseline, which was not yet incorporated in the trials assessed in the meta-analysis. ${ }^{1942}$ Table 3 summarizes adverse events in PARPi maintenance treatment in ovarian cancer in front-line and recurrent settings. ${ }^{18-20} 22-24$

Patients on treatment with PARPi will have adverse events, and especially in the maintenance setting they will require counseling as to importance of therapy so that it is not discontinued too quickly. It is important to maintain some degree of dose intensity, similar to validated doses/schedules, and they may require brief pauses in the initial months of treatment. In the event of a severe or grade $\geq 3$ toxicity, holding the PARPi and performing dose modifications is generally considered; however, hepatic function changes with rucaparib does not generally require a dose adjustment, whereas increases in the creatinine related to renal transporter may require careful monitoring but can persevere with therapy. A potential dose-response relationship has been described in he case of olaparib; ${ }^{434}$ however, in the case of niraparib, the baseline dose reduction in PRIMA was not associated with inferior results, which may be related to a high initial starting dose. ${ }^{19}$

Common and uncommon adverse events associated with PARPi treatment are presented in this review with recommendations 
FRONT-LINE MAINTENANCE

CONTINUATION MAINTENANCE

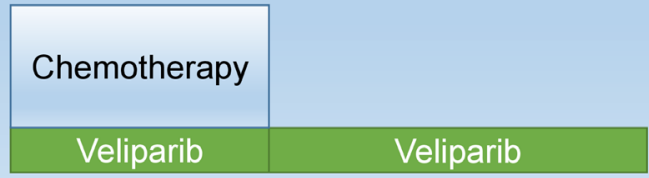

SWITCH MAINTENANCE

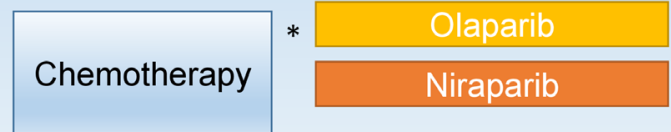

(2)

(3)

(1)

\section{PLATINUM-SENSITIVE MAINTENANCE}

\section{SWITCH MAINTENANCE}

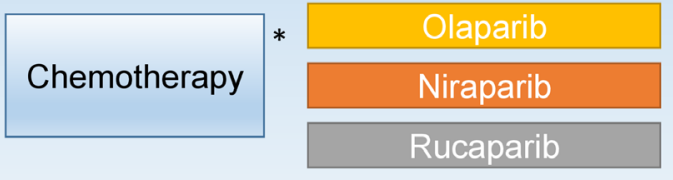

${ }^{*}$ Response to platinum-based chemotherapy. For specific trial selection criteria refer to Table 2.

(1) VELIA, NCT02470585 (2) SOLO1, NCT01844986 (3) PRIMA/ENGOT-OV26, NCT02655016 (4) SOLO2/ENGOT-Ov21, NCT01874353

(5) ENGOT-OV16/NOVA, NCT01847274 (6) ARIEL3, NCT01968213

Figure 1 Maintenance strategies in phase III clinical trials assessing poly (ADP-ribose) polymerase inhibitor (PARPi) treatment in ovarian cancer.

on management according to National Comprehensive Cancer Network (NCCN) among other guidelines, as well as expert opinion. The general non-hematologic dose modifications are summarized in Table 4. In maintenance studies, some of the symptoms that are reported early may be related to prior-chemotherapy effects, which subside over time or patients develop some tolerance or adaptation to some adverse events.

\section{Fatigue}

Fatigue remains one of the most common class effect adverse events, reported in $50 \%-70 \%$ of patients, mainly grade $1-2$ (Table 3). Fatigue was also captured in high frequency by the patient-reported outcomes. ${ }^{45}$ A longitudinal health-related QoL assessment in patients with maintenance niraparib treatment in platinum-sensitive recurrence showed that the patient-perceived lack of energy was worse at the initiation of the treatment, and improved relative to baseline over time ${ }^{45}$ In fact, in the VELIA clinical trial, veliparib throughout group, the PARPi was administered initially along with the chemotherapy, and only $23 \%$ of the patients in maintenance phase reported any grade of fatigue (Table 3). ${ }^{20}$

NCCN guidelines recommend physical activity for fatigue management; however, caution in determining level of activity is warranted specifically if there is concurrent treatment-related anemia or thrombocytopenia. ${ }^{46}$ Massage therapy and psychosocial interventions are also recommended to improve fatigue. ${ }^{46}$ optimizing treatment for sleep dysfunction and nutritional deficit/ imbalance may also be helpful. ${ }^{46}$

\section{Hematologic Toxicity}

Hematologic adverse events are very frequent class effect adverse events (Table 3), linked to the mechanism of action of the drug, trapping PARP $1 .{ }^{47}$ It is more frequent in the initial months of treatment and tends to recover over time, sometimes requiring dose interruptions or reductions. ${ }^{42}$ However, careful assessment over time is warranted, given the risk of late-onset hematologic adverse events.

Anemia is a common PARPi associated adverse event that occurs in $40 \%-60 \%$ of patients (Table 3 ), and may be less common with veliparib maintenance (Table 3). Generally, hemoglobin $(\mathrm{Hb})$ levels $<8 \mathrm{~g} / \mathrm{dL}$ require dose interruptions, and blood work should be monitored weekly until the hemoglobin level returns to $\geq 9 \mathrm{~g} / \mathrm{dL}^{13}$. Once recovered, the PARPi can be resumed at the same dose at first occurrence, or a lower dose level..$^{13}$ Clinicians may also manage grade 1-2 symptomatic anemia with short dose interruptions without decreasing the dose level. The American Association of Blood Banks (AABB) recommends a transfusion in those patients with hemoglobin levels $<7 \mathrm{~g} / \mathrm{dL}$, or higher levels if the patient is symptomatic or has significant co-morbidities, including cardiac, chronic pulmonary, and cerebral vascular disease. ${ }^{48}$ Other causes of anemia should be ruled out including iron, vitamin $\mathrm{B}_{12}$, or folate deficiencies and hypothyroidism.

Thrombocytopenia has been more commonly associated with treatment with niraparib (Table 3). In general, in the occurrence of platelet counts of $<100 \times 10^{9} \mathrm{cell} / \mathrm{L}$ PARPi treatment should be withheld and counts monitored weekly until platelet counts are $\geq 100 \times 10^{9}$ cells $/$ L. ${ }^{13}$ Once recovered, PARPi can be resumed at the same or reduced dose level. However, if the platelet count remains $<75 \times 10^{9}$ cells/L or at a second occurrence, a dose reduction should be considered. ${ }^{13}$ In the case of talazoparib, the recommended interruption threshold differs, and treatment may be continued if platelet counts are $\geq 50 \times 10^{9}$ cells/ $L$. ${ }^{15}$ Prophylactic 
Table 2 Phase III placebo-controlled trials assessing maintenance strategies with single-agent poly (ADP-ribose) polymerase inhibitors (PARPi) after response to platinum-based chemotherapy. Additionally, the three trials in platinum-sensitive settings included patients with $\geq 2$ lines of platinum therapy.

\begin{tabular}{|c|c|c|c|c|c|}
\hline Trial/PARPi & Histology & BRCA mutation & $\begin{array}{l}\text { HRD, excluding } \\
\text { BRCA (assay) }\end{array}$ & Residual disease & CA125 level \\
\hline \multicolumn{6}{|c|}{ Front-Line - Switch Maintenance } \\
\hline $\begin{array}{l}\text { SOLO1 } \\
\text { Olaparib }\end{array}$ & $\begin{array}{l}\text { HGS } 96 \% \\
\text { HGE } 2 \% \\
\text { Mixed } 2 \%\end{array}$ & $\begin{array}{l}\text { Germline } 99 \% \\
\text { Somatic } 1 \%\end{array}$ & N/A & N/A & No rising \\
\hline $\begin{array}{l}\text { PRIMA } \\
\text { Niraparib }\end{array}$ & $\begin{array}{l}\text { HGS } 95 \% \\
\text { HGE 3\% } \\
\text { Mixed 2\% }\end{array}$ & $\begin{array}{l}\text { Germline or somatic } \\
30 \%\end{array}$ & $\begin{array}{l}\text { HRD } 20 \% \\
\text { (Myriad Mychoice } \\
\text { cut-off: } \geq 42 \% \text { ) }\end{array}$ & $\leq 2 \mathrm{~cm}$ & $\begin{array}{l}\text { Normal or } 90 \% \downarrow \\
\text { with chemotherapy }\end{array}$ \\
\hline \multicolumn{6}{|c|}{ Front-Line - Continuation Maintenance in Three-Arm Design } \\
\hline $\begin{array}{l}\text { VELIA } \\
\text { Veliparib }\end{array}$ & HGS $100 \%$ & $\begin{array}{l}\text { Germline } 19 \% \\
\text { Somatic } 7 \%\end{array}$ & $\begin{array}{l}\text { HRD 29\% (Myriad } \\
\text { Mychoice cut-off: } \\
\geq 33 \% \text { ) }\end{array}$ & N/A & - \\
\hline \multicolumn{6}{|c|}{ Platinum-Sensitive Recurrence - Switch Maintenance (PARPi-Naïve) } \\
\hline $\begin{array}{l}\text { SOLO2 } \\
\text { Olaparib }\end{array}$ & $\begin{array}{l}\text { HGS } 91 \% \\
\text { HGE } 6 \% \\
\text { Mixed } 3 \%\end{array}$ & $\begin{array}{l}\text { Germline } 97 \% \\
\text { Somatic } 0 \%\end{array}$ & N/A & N/A & No rising \\
\hline $\begin{array}{l}\text { NOVA } \\
\text { Niraparib }\end{array}$ & $\begin{array}{l}\text { Predominantly } \\
\text { HGS }^{*}\end{array}$ & $\begin{array}{l}\text { Germline } 37 \% \\
\text { Somatic } 8 \%\end{array}$ & $\begin{array}{l}\text { HRD 29\% } \\
\text { (Myriad Mychoice } \\
\text { cut-off: } \geq 42 \% \text { ) }\end{array}$ & $\leq 2 \mathrm{~cm}$ & $\begin{array}{l}\text { Normal or } 90 \% \downarrow \\
\text { with chemotherapy }\end{array}$ \\
\hline $\begin{array}{l}\text { ARIEL3 } \\
\text { Rucaparib }\end{array}$ & $\begin{array}{l}\text { HGS } 95 \% \\
\text { HGE } 4 \% \\
\text { Mixed } 1 \%\end{array}$ & $\begin{array}{l}\text { Germline or somatic } \\
35 \%\end{array}$ & $\begin{array}{l}\text { LOH high } 28 \% \\
\text { (Foundation } \\
\text { medicine T5 cut-off: } \\
\geq 16 \% \text { ) }\end{array}$ & N/A & Normal \\
\hline
\end{tabular}

*Non-HGS with gBRCAm were also eligible. Number of patients with other histologies has not been reported.

HGE, high-grade endometrioid; HGS, high-grade serous; HRD, homologous recombination deficiency; LOH, loss of heterozygosity; mixed, HGS and HGE; N/A, not applicable; PARPi, poly (ADP-ribose) polymerase inhibitor.

platelet transfusion is recommended in those patients with a platelet count of $<10 \times 10^{9} \mathrm{cells} / \mathrm{L}$, or higher if evidence of active bleeding or invasive procedures are needed..$^{49}$ Given that patients with gynecologic tumors may bleed from necrotic tumor sites, individualization is required, and guidelines recommend to consider giving transfusion at a higher threshold, perhaps $20 \times 10^{9}$ cells/L. ${ }^{49}$ Furthermore, patients receiving anticoagulants or antiplatelet drugs should also consider interrupting these drugs and/or transfuse at a higher platelet count. ${ }^{13}$

Neutropenia of any grade has been reported in $20 \%$ of patients on maintenance PARPi treatment (Table 3), which can reach upwards of $50 \%$ in the case of niraparib. ${ }^{13}$ In general, if neutrophil levels are $<1000 / \mu \mathrm{L}$, PARPi treatment should be discontinued and monitored with weekly blood work; once the neutrophil level returns to $>1500 / \mu \mathrm{L}$ treatment can be resumed, and reduction to a lower dose level can be considered. ${ }^{13}$ Restarting the PARPi once neutropenia resolves to grade $2(\geq 1000 / \mu \mathrm{L})$ can also be considered. ${ }^{24}$ In specific cases, short treatment interruptions may also be considered for asymptomatic grade 3 neutropenia, without dose reductions. Febrile neutropenia is rare $(\leq 1 \%)$ when PARPi are administered as a single agent. ${ }^{18} 1924$ Continuous granulocyte growing factor use during PARPi treatment is not recommended. If continuous granulocyte growing factor is used in the event of a febrile neutropenia, growth factor support should be stopped at least 24 hours before restarting the study drug. ${ }^{18}$
Grade $\geq 3$ hematologic adverse events, especially thrombocytopenia, are more frequent with niraparib, in comparison with rucaparib, olaparib, and veliparib (Table 3). ${ }^{41}$ In fact, a retrospective analysis of NOVA and the dose escalation and expansion study data on niraparib identified that baseline body weight of $<77 \mathrm{~kg}$ or platelet count of $<150000 / \mu \mathrm{L}$ were significant predictors for early dose modification. ${ }^{42}$ The authors recommend a starting dose of $200 \mathrm{mg}$ daily in those patients weighing $<77 \mathrm{~kg}$ or with a platelet count $<150 \times 10^{9} \mathrm{cells} / \mathrm{L}$. In fact, the PRIMA trial assessing frontline maintenance niraparib was amended in 2017 with this recommendation, and $35 \%$ of the patients had individualized start dose criteria, with an improvement in hematologic adverse events. ${ }^{19}$ The baseline dose modification has not yet been included in the US prescribing information. ${ }^{13}$ The European Medicines Agency (EMA) suggests that a starting dose of $200 \mathrm{mg}$ in women weighing $<58 \mathrm{~kg}$ may be considered. ${ }^{50}$ Talazoparib has also been linked to frequent grade $\geq 3$ hematologic adverse events (anemia 39\%, neutropenia $21 \%$, and thrombocytopenia $15 \%$ ), but data in ovarian cancer are more limited. ${ }^{15}$

In general, complete blood counts should be monitored weekly for the first month, monthly during the first year of treatment, and periodically after this time. ${ }^{13}$ Weekly blood work should also be considered following a grade 3 or 4 hematologic event until recovery. ${ }^{13}$ If hematologic toxicity does not recover within 4 weeks, clinicians should consider a referral to an hematologist for a bone 


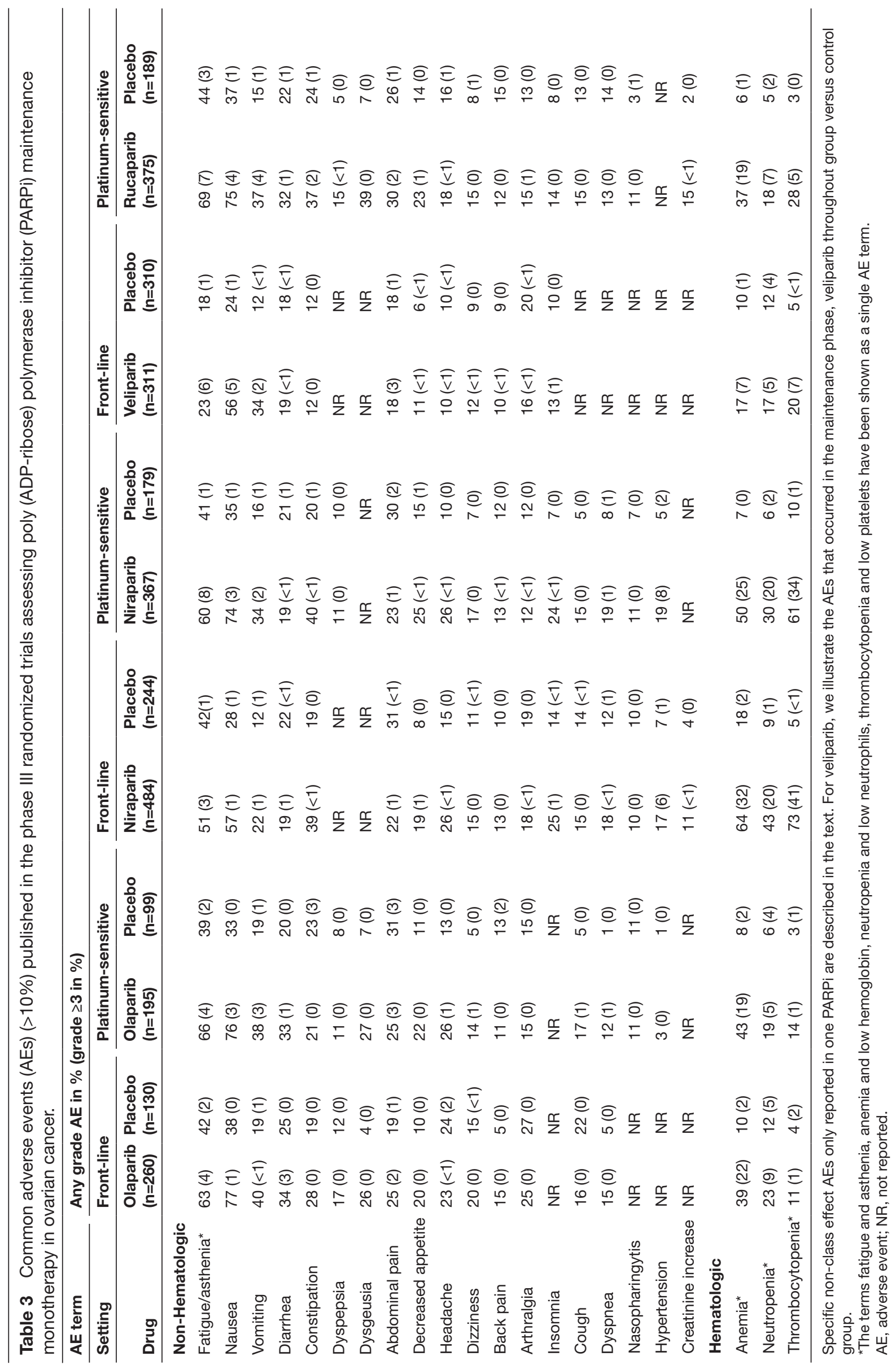


Table 4 General non-hematologic dose modifications for poly (ADP-ribose) polymerase inhibitor (PARPi) treatment

\begin{tabular}{ll}
\hline Severity & Management \\
\hline Grade 1 & $\begin{array}{l}\text { Continue treatment } \\
\text { Consider dose interruptions } \\
\text { or reductions if considered } \\
\text { clinically intolerable by the } \\
\text { patient, despite adequate } \\
\text { symptom management } \\
\text { Continue treatment }\end{array}$ \\
Grade 2 & $\begin{array}{l}\text { Consider dose interruptions } \\
\text { or reductions if it does not } \\
\text { improve with symptom } \\
\text { management, or if considered } \\
\text { clinically intolerable by the } \\
\text { patient }\end{array}$ \\
is not feasible or AE persists & $\begin{array}{l}\text { Withhold for a maximum of } \\
28 \text { days or until resolution } \\
\text { of adverse reaction; then, } \\
\text { despite treatment }\end{array}$ \\
$\begin{array}{l}\text { Grade } \geq 3 \text { lasting }>28 \text { days } \\
\text { on the lowest dose-level }\end{array}$ & $\begin{array}{l}\text { If AE persists despite } \\
\text { adequate management, } \\
\text { permanently discontinue } \\
\text { medication }\end{array}$ \\
&
\end{tabular}

$\mathrm{AE}$, adverse event.

marrow biopsy/aspirate, and blood sample for cytogenetics to rule out myelodysplastic syndrome/acute myeloid leukemia. ${ }^{12}$ Management is discussed in the rare adverse events section.

\section{Gastrointestinal Disorders}

Nausea and vomiting are also considered common class effect adverse events of PARPi (Table 3). Niraparib, olaparib, rucaparib, and veliparib as maintenance treatments would be categorized as moderate emetic risk as per the NCCN guidelines (emesis in $>30 \%$ of patients). ${ }^{20}{ }^{51} \mathrm{~A}$ phase III study assessing talazoparib monotherapy in breast cancer categorizes it as minimal to low emetic risk. ${ }^{8}$ Nausea is an early event on treatment, and is considered to be worse during the first cycles. In a health-related QoL study of niraparib, nausea increased from baseline at cycle 2 of treatment, but steadily declined at later time points, approaching to baseline levels. ${ }^{45}$

The use of metoclopramide, prochlorperazine, or promethazine 30 min prior to the PARPi is a good treatment option for its management, especially at the beginning of the treatment. ${ }^{52}$ The administration of food 30-60 min before the PARPi may also help to prevent emesis. In patients that experience anticipatory nausea and vomiting, benzodiazepines may be considered. ${ }^{52}$ Although the NCCN guidelines recommend the use of a serotonin (5-HT3) receptor antagonist, such as ondansetron, with moderate emetogenic agents, it is not generally recommended in the case of PARPi given its continuous administration and increased risk of constipation. ${ }^{52}{ }^{53}$ Other options for nausea and vomiting management include steroids, domperidone, olanzapine, dronabinol, haloperidol, or scopolamine transdermal patch. ${ }^{52}$ Given that PARPi are administered daily, long-term steroid use for nausea/vomiting management should be avoided, but may be used short-term in acute cases. Severe (grade $\geq 3$ ) nausea and/or vomiting is infrequent (Table 3); in the event, treatment should be withheld until symptom recovery and restarted at a lower dose level. A neurokinine-1 receptor antagonist, such as aprepitant, should be avoided while on treatment with olaparib due to drug interactions (Table 1).

Dyspepsia has been reported in $\sim 10 \%-20 \%$ of patients on maintenance PARPi (Table 3; maintenance veliparib no data). Clinicians may advise patients to have small meals and assess potential dietary triggers (eg, fatty food, spices, alcohol). In cases where dyspepsia remains uncontrolled, proton pump inhibitor therapy may be indicated; ${ }^{54}$ and if these are ineffective, tricyclic antidepressants or prokinetics may be recommended. ${ }^{54}$ In certain cases, non-invasive test Helicobacter pylori or upper endoscopy may be considered to rule out other causes of dyspepsia. Treatment with rucaparib may increase the effect of omeprazole. ${ }^{17}$ Dysgeusia has been reported in $\sim 10 \%-40 \%$ of patients, more commonly with rucaparib (Table 3). Ensuring that patients maintain adequate oral hygiene care may also be helpful for dysgeusia management. ${ }^{55}$

Diarrhea and/or constipation have frequently occurred in approximately one-third of patients treated with PARPi maintenance, and are generally grade 1-2 (Table 3). Other frequent gastrointestinal disorders include abdominal pain and decrease in appetite; however, rates of abdominal pain seem to be similar in the placebo arm, and may also be related to underlying disease (Table 3). Decrease in appetite has been described in approximately $20 \%$ of patients on maintenance PARPi treatment, and was considered severe in $<1 \%$ of patients (Table 3). Evaluation or monitoring of weight loss might be helpful; and patient and family education, nutrition consultation, and evaluation of other potential endocrine abnormalities, including thyroid function, may be considered by clinicians. ${ }^{56}$

\section{Laboratory Abnormalities: Hepatic and Renal Function}

Transient transaminase elevation is an adverse event commonly seen with rucaparib during the initial cycles of treatment. ${ }^{24}$ Maintenance rucaparib in platinum-sensitive patients was associated with alanine aminotransferase (ALT) and/or aspartate aminotransferase (AST) increase in $34 \%$ of cases (grade $\geq 3$ in $10 \%$ ); in general self-limiting, not associated with other signs of liver toxicity, and recovery to normal limits was generally achieved within 3-4 cycles of treatment. ${ }^{24}$ In the event of a grade 4 ALT/AST elevation, rucaparib should be held until values return to grade $\leq 2$, and treatment can be resumed with a dose reduction and weekly monitoring for at least 3 weeks. In the event of a grade 3 ALT/AST elevation, treatment should be individualized, and continuation of treatment under careful monitoring can be considered if bilirubin is normal and alkaline phosphatase $<3$ of institutional normal limit. If levels do not decline within 2 weeks, treatment should be interrupted until resolution to grade $\leq 2$, and treatment can be resumed at the same dose or lower dose level. Rucaparib treatment discontinuations due to ALT/AST elevation occurred in $0.5 \%$ of the patients in the ARIEL3 trial. ${ }^{24}$ Transaminase elevation has also been described in $~ 5 \%$ olaparib and $\sim 10 \%$ niraparib treatment regimens. ${ }^{1322}$ In the event of hepatic toxicity, other etiologies for liver enzyme elevation may be ruled out.

Elevations in creatinine have been described in approximately $10 \%-12 \%$ of patients across different PARPi. ${ }^{19} 2224$ In fact, PARPi have in-target effects in renal transporters (such as MATE-1, MATE-2, OCT-1, OCT-2) that secrete creatinine into the urine, but are not usually not associated with a true renal injury. ${ }^{24} \mathrm{~A}$ retrospective 
study showed that serum creatinine elevation in patients on PARPi may not be associated with a decrease in glomerular filtration rate as measured by renal scan. ${ }^{57}$ In the event of a significant creatinine elevation, other causes should be ruled out and a renal scan may be considered. If the glomerular filtration rate remains maintained, dose modifications or treatment interruptions can be avoided.

\section{Respiratory Disorders}

Dyspnea and/or cough occur in approximately $10 \%-20 \%$ of patients on PARPi treatment, generally grade 1-2. Comprehensive symptom assessment is required, as well as treatment of other potential reversible co-morbid conditions. ${ }^{56}$ If new or worsening pulmonary symptoms are found treatment should be withheld, and a diagnostic workup including a high-resolution computed tomography scan should be performed, to exclude pneumonitis. ${ }^{18}$ If no abnormality is seen in the investigations and symptoms resolve, restarting the treatment can be considered. ${ }^{18}$

Pneumonitis has been described in $<1 \%$ of patients treated with olaparib. ${ }^{12}$ Symptomatic patients with radiographic findings of pneumonitis should hold the treatment, undergo investigations including pulmonary function tests and bronchoscopy, and initiate treatment with corticosteroids and antibiotics as appropriate. More data are required regarding low-grade pneumonitis and potential discontinuation of PARPi.

Nasopharyngitis has been described in approximately $10 \%$ of patients on maintenance PARPi (Table 3; maintenance veliparib no data). Generally, decongestants may be used (eg, diphenhydramine, loratadine) for management; if very symptomatic, fluticasone nasal spray may also be considered. ${ }^{58}$

\section{Nervous System and Psychiatric Effects}

Insomnia or headache have been reported during maintenance PARPi treatment in $\sim 10 \%-25 \%$ of patients, and are usually grade 1-2 (Table 3). In fact, preclinical studies have shown that PARP1 is involved in the regulation of circadian gene transcription. ${ }^{59}$ Sleep hygiene education, cognitive behavioral treatment, and/or pharmacologic approaches can be considered for its management in refractory cases ${ }^{56}$ Similarly, quantity and intensity of headache should be characterized, and pharmacological treatment may be considered depending on severity and interference of the pain. ${ }^{60}$ Dizziness was also reported in $\sim 15 \%$ of patients across the different maintenance PARPi treatments (Table 3). In the event of neurologic adverse events other causes, such as central nervous system involvement, endocrine, or other laboratory abnormalities, may also be ruled out.

Preclinical studies have shown a potential favorable modulation of nerve-related pain with PARPi treatment, as well as decrease in neuroinflammation, ${ }^{61}{ }^{62}$ but this has not been proven in clinical practice to date. A meta-analysis, including five placebo-controlled clinical trials (only one assessing maintenance treatment) and 843 subjects treated with olaparib or veliparib, found that the overall relative risk of developing neuropathy with PARPi was 1.06 (95\% Cl 1 to 1.4). ${ }^{63}$ The PRIMA clinical trial assessing niraparib maintenance in a platinum-sensitive setting incorporated a neuropathy questionnaire during the first six cycles of treatment; ${ }^{45}$ however, the questionnaire was only employed for a limited period of time, and potential long-term effects cannot be judged. The comparison between the placebo and niraparib arm have not been reported, but seem numerically similar.

\section{Dermatologic Toxicity}

Dermatologic adverse events have been mainly described with rucaparib and niraparib treatment. ${ }^{1324}$ In the ARIEL3 clinical trial, $17 \%$ of the patients receiving rucaparib reported photosensitivity, $12 \%$ rash, and $13 \%$ pruritus, which were mainly grade $1-2^{24}$. In the SOL02 trial assessing olaparib maintenance, $1 \%$ of the patients receiving olaparib experienced a rash. ${ }^{22}$ Patients on PARPi treatment should be instructed to use sun protection, and a dermatology referral may be requested as needed.

\section{Cardiovascular Toxicity}

Cardiovascular effects, including hypertension, hypertensive crisis, tachycardia, and palpitation, have been reported as adverse events mainly related to niraparib. ${ }^{64} \mathrm{An}$ in vitro pharmacology screen showed that niraparib has an off-target pharmacologic inhibition of dopamine transporter, norepinephrine transporter, and serotonine transporter, which may explain the distinct cardiovascular side effect profile of the drug. ${ }^{64}$ In the NOVA trial, $19 \%$ of the patients on treatment with niraparib experienced grade $\geq 3$ hypertension in $8 \%$ of cases; and $10 \%$ of the patients experienced palpitations, all grade $1-2 .{ }^{23}$ Blood pressure should be regularly monitored in patients on treatment with niraparib, especially in those patients with prior history of cardiovascular disease. If hypertension is diagnosed, non-pharmacologic and pharmacologic therapy should be considered as per the guidelines. ${ }^{65}$

\section{Rare Adverse Events}

Myelodysplastic syndrome/acute myeloid leukemia is a serious rare adverse event related to PARPi treatment, found in approximately $1 \%$ of patients. ${ }^{12-14}$ Prior platinum therapy and other DNA damaging agents are added risk factors for the development of myelodysplastic syndrome/acute myeloid leukemia, as well as the presence of germline BRCAm. ${ }^{66}{ }^{67}$ If unexplained or prolonged pancytopenia is found, patients should be referred to a hematologist for consideration for bone marrow aspiration. If myelodysplastic syndrome/acute myeloid leukemia is diagnosed, treatment with PARPi should be permanently discontinued.

\section{Patient-Reported Outcomes}

None of the PARPi trials assessing maintenance strategies in ovarian cancer have demonstrated an improvement of the prespecified primary QoL analysis, and would not be expected to do so given treatment with an active agent is being administered during a time when patients do not have active disease or symptoms. The trials assessing olaparib maintenance treatment (first-line and platinum-sensitive recurrence) used the Functional Assessment of Cancer Therapy - Ovarian Cancer (FACT-0) tool, which has specific cancer site-adjusted questionnaires, as well as assessment of physical, social/family, emotional, and functional well-being. ${ }^{6} 1868$ The changes in FACT from baseline can be measured through the Trial Outcome Index (TOI) score. ${ }^{6}$ The ovarian cancer symptom index (FOSI) is a shorter, more focused subset of the FACT-0 items, and comes in two forms: the original eight-item form and the more comprehensive 18-item form (NFOSI-18). NFOSI-18 was incorporated in trials assessing veliparib and rucaparib in ovarian cancer, whereas FOSI was used in the trials assessing niraparib 
Table 5 Health-related quality-of-life measures incorporated in maintenance poly (ADP-ribose) polymerase inhibitor (PARPi) trials

\begin{tabular}{|c|c|c|c|c|c|}
\hline $\begin{array}{l}\text { Study/ } \\
\text { PARPi }\end{array}$ & $\begin{array}{l}\text { Outcome } \\
\text { (primary/ } \\
\text { relevant PRO) }\end{array}$ & $\begin{array}{l}\text { Statistical } \\
\text { considerations }\end{array}$ & Time frame & Completion rate & Results \\
\hline $\begin{array}{l}\text { SOLO1 } \\
\text { Olaparib }\end{array}$ & FACT-O & $\begin{array}{l}\text { Differences in TOI from } \\
\text { baseline to } 2 \text { years. } \\
\text { Significant } 10 \text { point } \\
\text { difference }\end{array}$ & $\begin{array}{l}\text { Baseline, D29 } \\
\text { Q12 W for } 3 \text { years } \\
\text { Q24 W until data cut-off }\end{array}$ & Baseline-W97: >80\% & $\begin{array}{l}\text { TOI score NS } \\
-3.00 \text { points } \\
(95 \% \mathrm{Cl}-4.78 \text { to } \\
-1.22)\end{array}$ \\
\hline \multicolumn{6}{|c|}{ Platinum-Sensitive Maintenance } \\
\hline $\begin{array}{l}\text { SOLO2 } \\
\text { Olaparib }\end{array}$ & $\begin{array}{l}\text { FACT-O } \\
\text { EQ-5D-5L }\end{array}$ & $\begin{array}{l}\text { Differences in TOI from } \\
\text { baseline to } 12 \text { months }\end{array}$ & $\begin{array}{l}\text { Baseline, W5, W13 } \\
\text { Q12 W for } 2 \text { years or data } \\
\text { cut-off } \\
30 \text { D from discontinuation, } \\
\text { and Q12 W during follow- } \\
\text { up (patients with PD) }\end{array}$ & $\begin{array}{l}\text { At W49: }>90 \% \\
\text { End of treatment: } \\
>65 \%\end{array}$ & $\begin{array}{l}\text { TOI score NS } \\
-0.03 \text { points } \\
(-2.19 \text { to } 2.13) \\
p=0.98\end{array}$ \\
\hline $\begin{array}{l}\text { NOVA } \\
\text { Niraparib }\end{array}$ & $\begin{array}{l}\text { FOSI } \\
\text { EQ-5D-5L } \\
\text { EQ-VAS }\end{array}$ & Descriptive & $\begin{array}{l}\text { Baseline } \\
\text { Q8 W for } 14 \text { cycles } \\
\text { Q12 W thereafter } \\
\text { Discontinuation and } 8 \mathrm{~W} \\
\text { after }\end{array}$ & $\begin{array}{l}\text { FOSI baseline-cycle } \\
6:>85 \% \\
\text { Post-PD: }>75 \%\end{array}$ & $\begin{array}{l}\text { FOSI and EQ-5D- } \\
5 \mathrm{~L} \text { N } \\
\text { Minimal } \\
\text { changes during } \\
\text { maintenance and } \\
\text { post-PD }\end{array}$ \\
\hline $\begin{array}{l}\text { ARIEL3 } \\
\text { Rucaparib }\end{array}$ & $\begin{array}{l}\text { NFOSI-18 } \\
\text { EQ-5D-3L }\end{array}$ & $\begin{array}{l}\text { DRS-P: significant } 4 \\
\text { point difference } \\
\text { Total score: significant } \\
8 \text { point difference } \\
\text { Step-down procedure } \\
\text { for three subgroups } \\
\text { (BRCAm, HRD, } \\
\text { intention-to-treat) }\end{array}$ & $\begin{array}{l}\text { Baseline } \\
\text { D1 cycle } \\
\text { Discontinuation and } 28 \text { D } \\
\text { after }\end{array}$ & NR & $\begin{array}{l}\text { FOSI DRS-P } \\
\text { BRCAm NS } \\
\text { Separate } \\
\text { publication } \\
\text { awaited }\end{array}$ \\
\hline
\end{tabular}

D, day; DRS-P, Disease-Related Symptoms Physical subscale; EORTC-QLQ-C30/OV28, EORTC ovarian cancer module; EQ-5D-5L, European Quality of Life-5 Dimensions; EQ-VAS, EuroQol-Visual Analogue Scale; FACT-O, Functional Assessment of Cancer Therapy - Ovarian Cancer; HRD, homologous recombinant deficiency; NFOSI-18, 18-item form of FOSI questionnaire; NS, not significant; PD, progressive disease; PRO, patient-reported outcome; TOI, Trial Outcome Index; W, weeks.

maintenance. ${ }^{2024} 45$ Finally, European Quality of Life-5 Dimensions tool (EQ-5D-5L), which measures five domains (mobility, self-care, usual activities, pain/discomfort, and anxiety/depression), and the ovarian cancer module of the European Organization for Research and Treatment of Cancer core questionnaire (EORTC-QLQ-C30/ OV28) were also used in some of the studies. ${ }^{19} 2245$ The different tools and outcomes are summarized in Table 5.

Other contemporary health-related QoL measures have been used in the maintenance PARPi trials. In fact, SOL02 incorporated other secondary planned novel QoL measures to assess the duration of good QoL, assessing the potential value of delaying disease recurrence, over and above treatment-related adverse events. ${ }^{68}$ The time without significant symptoms of toxicity (TWiST) assessed the period without grade $\geq 2$ nausea, vomiting, or fatigue from randomization to disease progression, and was significantly better in the olaparib arm (olaparib 15 months vs placebo 7.7 months; difference $7.3,95 \% \mathrm{Cl} 4.7$ to 9 ). ${ }^{68}$ The quality-adjusted progression-free survival (QAPFS) was calculated with the EQ-5D-5L questionnaire, and was significantly better in the olaparib arm (olaparib 14 months vs placebo 7.2 months; difference $6.7,95 \% \mathrm{Cl} 5$ to 8.6$).{ }^{68}$ TWIST and QAPFS give an overview of the time without significant treatment toxicity and disease-related symptoms over time, but were not the primary patient-reported outcomes of the trial. TWIST and the quality-adjusted analysis (quality-adjusted TWIST and QAPFS) has also been assessed in the ARIEL3 clinical trial; being favorable for rucaparib in comparison to placebo in the intention-to-treat 


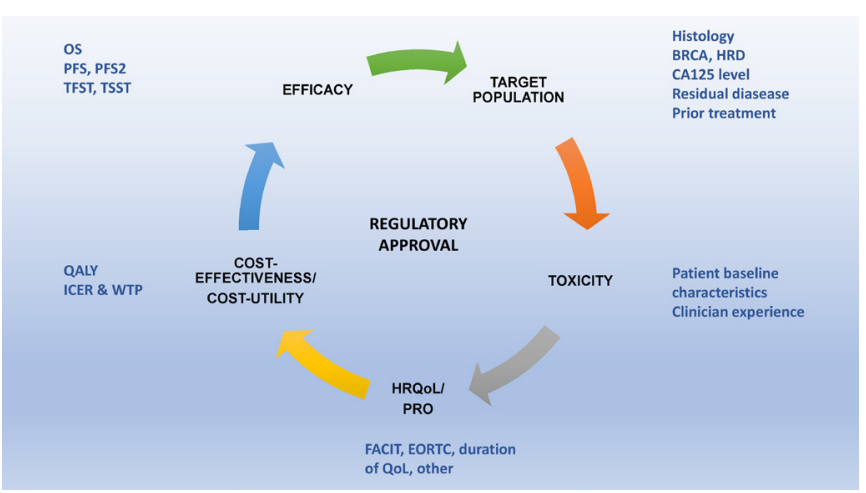

Figure 2 Criteria that may help clinicians in poly (ADPribose) inhibitor (PARPi) treatment selection for ovarian cancer. EORTC, European Organization for Research and Treatment of Cancer; FACIT, Functional Assessment of Chronic Illness Therapy; HR Qol, health-related quality of life; ICER, incremental cost-effectiveness ratio; Pfs2, progression after the next line of therapy; PRO: patient-reported outcomes; QALY, quality-adjusted life-year; TFST, time to first subsequent therapy; TSST, time to second subsequent therapy; WTP, willingness to pay.

population and all subgroups. ${ }^{69}$ In the NOVA trial assessing maintenance niraparib in platinum-sensitive recurrence, a longitudinal assessment of the patients' QoL was performed, which remained stable over time. ${ }^{45}$ One of the most common adverse events of niraparib is hematologic toxicity, and disutility analyses done to understand the relationship between safety and patient-reported outcome responses showed no significant QoL impairment. ${ }^{45}$ In fact, all symptoms, except nausea, remained either stable or improved over time. ${ }^{45}$

\section{Patient Selection for Maintenance PARPi}

Multiple options regarding maintenance PARPi treatment may be available for patients, and several aspects might be helpful for physicians at the time of clinical decision-making (Figure 2). It is important to highlight that mature overall survival data from the phase III maintenance trials are awaited; and to date, no significant differences in the primary QoL measures have been detected with respect to placebo. ${ }^{618-2022-24}$

- An important consideration in choosing PARPi corresponds to the specific regulatory agency approval, as well as funding. In the first-line maintenance setting, olaparib remains the only PARPi approved by the Food and Drugs Administration (FDA) and the European Medicines Agency (EMA) for germline or somatic BRCAm carriers. ${ }^{12}$ Front-line niraparib maintenance therapy is under review by the FDA. In platinum-sensitive recurrence, maintenance treatment with olaparib, rucaparib, and niraparib have been granted approval by the FDA and EMA. ${ }^{12-14}$ As a treatment strategy (non-maintenance) and prior $\geq 3$ lines of chemotherapy, the FDA has labeled olaparib in germline BRCAm carriers and niraparib in HRD patients, whereas rucaparib has been approved in those with $\geq 2$ lines of chemotherapy and a germline or somatic BRCAm. ${ }^{12-14}$ Rucaparib is the only PARPi approved as a non-maintenance treatment by the EMA for patients with $>2$ prior lines of chemotherapy, that are platinum-sensitive and non-eligible for platinum, and harbor a germline or somatic BRCAm.
- There were significant differences in the selection criteria of the trials assessing PARPi maintenance in terms of residual disease, CA125 levels, germline and somatic BRCA status, HRD companion diagnostics, and their thresholds (Table 2). ${ }^{18-2022-24}$

- The differences in toxicity (type of adverse events, severity, and frequency) should be balanced with patients' baseline characteristics; however, clinicians should prescribe a PARPi that they feel comfortable using and managing. Once the expertise in managing a certain PARPi is built, using the same drug may be considered.

- Cost-effectiveness can be a determining factor; however, further analyses are required. A recent study in platinumsensitive ovarian cancer demonstrated that niraparib had a higher quality-adjusted life-years (QALYs) compared with routine surveillance, olaparib, and rucaparib. ${ }^{70}$ This study has been criticized mainly due to comparability issues between the groups. ${ }^{71}$ Further independent cost-utility and costeffectiveness analysis are required in front-line and recurrence settings.

- Finally, the role of 'PARP after PARP' is a key question being urgently investigated. The best treatment option at the time of PARPi progression remains unclear; however, retrospective data suggest that there is no significant clinical cross-resistance between PARPi and platinum chemotherapy and, as such, continues to be the treatment of choice in platinum-sensitive patients. $^{72}$ Several randomized studies are assessing the role of re-treatment with PARPi maintenance (NCT03106987). A recent phase II study assessed the combination of PARPi and anti-angiogenics in the post-PARP setting. ${ }^{37}$ In the precision medicine era, assessment of the mechanism of resistance to PARPi on an individual patient basis may unravel the best treatment strategy and, ultimately, potential PARPi combinations.

\section{CONCLUSIONS}

PARPi treatment has dramatically changed the treatment landscape of some women with high-grade serous ovarian cancer, with long-term responders occasionally on treatment for years. ${ }^{25}$ The treatment-related adverse events are sometimes class effects and are seen in different frequencies across the different PARPi, such as hematologic toxicity, fatigue, nausea, and vomiting. Some adverse events tend to be more drug specific, for instance AST/ ALT increase with rucaparib and hypertension with niraparib. Other potential rare, but life-threatening, adverse events include myelodysplastic syndrome/acute myeloid leukemia and pneumonitis. Expert management of treatment is warranted to ensure patients' safety and dose intensity.

Correction notice Since the online publication of this article, the authors noticed that Table 3 was formatted incorrectly. Veliparib appeared under the table heading 'Platinum-sensitive' instead of the table heading 'Front-line'. This has now been corrected.

Twitter Ainhoa Madariaga @AinhoaMada

Contributors All authors contributed in writing and approving the final manuscript.

Funding The authors have not declared a specific grant for this research from any funding agency in the public, commercial or not-for-profit sectors.

Competing interests VB was previously on the advisory board for olaparib with $A Z$ and received a previous honorarium for a presentation with $A Z$. $A 0$ is on the steering committee of GSK, AZ and Clovis (uncompensated), and is PI on clinical 
trials for AZ, GSK, and Clovis. SL declares honaria from Roche, AZ, GSK, Merck, and is Co-Inv and PI on a number of different clinical trials.

\section{Patient consent for publication Not required.}

Provenance and peer review Not commissioned; externally peer reviewed.

Open access This is an open access article distributed in accordance with the Creative Commons Attribution Non Commercial (CC BY-NC 4.0) license, which permits others to distribute, remix, adapt, build upon this work non-commercially, and license their derivative works on different terms, provided the original work is properly cited, an indication of whether changes were made, and the use is noncommercial. See: http://creativecommons.org/licenses/by-nc/4.0/.

\section{ORCID iD}

Ainhoa Madariaga http://orcid.org/0000-0001-7166-9762

\section{REFERENCES}

1 Noone AM, Howlader N, Krapcho M, et al. SEER cancer statistics review, 1975-2015, National Cancer Institute. Bethesda, MD. Available: https://seer.cancer.gov/csr/1975_2015/

2 Ramalingam P. Morphologic, immunophenotypic, and molecular features of epithelial ovarian cancer. Oncology 2016;30:166-76.

3 Kurman RJ, Carcangiu ML, Herrington CS. WHO classification of tumours of the female reproductive organs. International Agency for Research on Cancer, 2014.

4 Cancer Genome Atlas Research Network. Integrated genomic analyses of ovarian carcinoma. Nature 2011;474:609-15.

5 Li X, Heyer W-D. Homologous recombination in DNA repair and DNA damage tolerance. Cell Res 2008;18:99-113.

6 Madariaga A, Rustin GJS, Buckanovich RJ, et al. Wanna get away? Maintenance treatments and chemotherapy holidays in gynecologic cancers. Am Soc Clin Oncol Educ Book 2019;39:e152-66.

7 Farmer H, McCabe N, Lord CJ, et al. Targeting the DNA repair defect in BRCA mutant cells as a therapeutic strategy. Nature 2005;434:917-21.

8 Litton JK, Rugo HS, Ettl J, et al. Talazoparib in patients with advanced breast cancer and a germline BRCA mutation. $N$ Engl J Med 2018;379:753-63.

9 Golan T, Hammel P, Reni M, et al. Maintenance olaparib for germline BRCA-mutated metastatic pancreatic cancer. $N$ Engl J Med 2019;381:317-27.

10 Lheureux S, Mirza M, Coleman R. The DNA repair pathway as a target for novel drugs in gynecologic cancers. J Clin Oncol 2019;37:2449-59.

11 Murai J, Huang S-yinN, Das BB, et al. Trapping of PARP1 and PARP2 by clinical PARP inhibitors. Cancer Res 2012;72:5588-99.

12 LYNPARZA® (olaparib). U.S. Food and Drug Administration website. Available: https://www.accessdata.fda.gov/drugsatfda_docs/label/ 2018/208558s001lbl.pdf [Accessed on 20 Dec 2019].

13 ZEJULATM (niraparib) capsules. U.S. Food and Drug Administration website. Available: https://www.accessdata.fda.gov/drugsatfda_ docs/label/2017/208447lbl.pdf [Accessed on 20 Dec 2019].

14 RUBRACA® (rucaparib) tablets. U.S. Food and Drug Administration website. Available: https://www.accessdata.fda.gov/drugsatfda docs/label/2018/209115s003lbl.pdf [Accessed on 20 Dec 2019].

15 TALZENNA ${ }^{\mathrm{TM}}$ (talazoparib) capsules. U.S. Food and Drug Administration website. Available: https://www.accessdata.fda.gov/ drugsatfda_docs/label/2018/211651s000lbl.pdf [Accessed on 4 Jan 2020].

16 Boussios S, Karihtala P, Moschetta M, et al. Veliparib in ovarian cancer: a new synthetically lethal therapeutic approach. Invest New Drugs 2020;38:181-193.

17 Xiao JJ, Nowak D, Ramlau R, et al. Evaluation of drug-drug interactions of rucaparib and CYP1A2, CYP2C9, CYP2C19, CYP3A, and P-gp substrates in patients with an advanced solid tumor. Clin Transl Sci 2019;12:58-65.

18 Moore K, Colombo N, Scambia G, et al. Maintenance olaparib in patients with newly diagnosed advanced ovarian cancer. $N$ Engl J Med 2018;379:2495-505.

19 González-Martín A, Pothuri B, Vergote I, et al. Niraparib in patients with newly diagnosed advanced ovarian cancer. $N$ Engl J Med 2019;381:2391-402.

20 Coleman RL, Fleming GF, Brady MF, et al. Veliparib with first-line chemotherapy and as maintenance therapy in ovarian cancer. $N$ Engl J Med 2019;381:2403-15.

21 Ledermann J, Harter P, Gourley C, et al. Olaparib maintenance therapy in platinum-sensitive relapsed ovarian cancer. $N$ Engl $\mathrm{J}$ Med 2012;366:1382-92.
22 Pujade-Lauraine E, Ledermann JA, Selle F, et al. Olaparib tablets as maintenance therapy in patients with platinum-sensitive, relapsed ovarian cancer and a BRCA1/2 mutation (SOLO2/ENGOT-Ov21): a double-blind, randomised, placebo-controlled, phase 3 trial. Lancet Oncol 2017;18:1274-84.

23 Mirza MR, Monk BJ, Herrstedt J, et al. Niraparib maintenance therapy in platinum-sensitive, recurrent ovarian cancer. $N$ Engl J Med 2016;375:2154-64.

24 Coleman RL, Oza AM, Lorusso D, et al. Rucaparib maintenance treatment for recurrent ovarian carcinoma after response to platinum therapy (ARIEL3): a randomised, double-blind, placebo-controlled, phase 3 trial. Lancet 2017;390:1949-61.

25 Lheureux S, Lai Z, Dougherty BA, et al. Long-term responders on olaparib maintenance in high-grade serous ovarian cancer: clinical and molecular characterization. Clin Cancer Res 2017;23:4086-94.

26 Longo DL. Personalized medicine for primary treatment of serous ovarian cancer. N Engl J Med 2019;381:2471-4.

27 Lheureux S, Braunstein M, Oza AM. Epithelial ovarian cancer: evolution of management in the era of precision medicine. $C A$ Cancer J Clin 2019;69:280-304.

28 Gelmon KA, Tischkowitz M, Mackay $\mathrm{H}$, et al. Olaparib in patients with recurrent high-grade serous or poorly differentiated ovarian carcinoma or triple-negative breast cancer: a phase 2, multicentre, open-label, non-randomised study. Lancet Oncol 2011;12:852-61.

29 Domchek SM, Aghajanian C, Shapira-Frommer R, et al. Efficacy and safety of olaparib monotherapy in germline BRCA1/2 mutation carriers with advanced ovarian cancer and three or more lines of prior therapy. Gynecol Oncol 2016;140:199-203.

30 Moore KN, Secord AA, Geller MA, et al. Niraparib monotherapy for late-line treatment of ovarian cancer (QUADRA): a multicentre, openlabel, single-arm, phase 2 trial. Lancet Oncol 2019;20:636-48.

31 Swisher EM, Lin KK, Oza AM, et al. Rucaparib in relapsed, platinum-sensitive high-grade ovarian carcinoma (ARIEL2 Part 1): an international, multicentre, open-label, phase 2 trial. Lancet Oncol 2017;18:75-87.

32 Kristeleit R, Shapiro Gl, Burris HA, et al. A phase I-II study of the oral PARP inhibitor rucaparib in patients with germline $B R C A 1 / 2-$ mutated ovarian carcinoma or other solid tumors. Clin Cancer Res 2017;23:4095-106.

33 Oza AM, Tinker AV, Oaknin A, et al. Antitumor activity and safety of the PARP inhibitor rucaparib in patients with high-grade ovarian carcinoma and a germline or somatic BRCA1 or BRCA2 mutation: integrated analysis of data from study 10 and ARIEL2. Gynecol Oncol 2017;147:267-75.

34 Oza AM, Cibula D, Benzaquen AO, et al. Olaparib combined with chemotherapy for recurrent platinum-sensitive ovarian cancer: a randomised phase 2 trial. Lancet Oncol 2015;16:87-97.

35 Ray-Coquard I, Pautier P, Pignata S, et al. Olaparib plus bevacizumab as first-line maintenance in ovarian cancer. $N$ Engl J Med 2019;381:2416-28.

36 Liu JF, Barry WT, Birrer M, et al. Overall survival and updated progression-free survival outcomes in a randomized phase II study of combination cediranib and olaparib versus olaparib in relapsed platinum-sensitive ovarian cancer. Ann Oncol 2019;30:551-7.

37 Lheureux S, Oaknin A, Garg S, et al. Evolve: a post PARP inhibitor clinical translational phase II trial of cediranib-olaparib in ovarian cancer-A Princess Margaret Consortium - GCIG phase II trial. J Clin Oncol 2019;37:5521.

38 Mirza MR, Åvall Lundqvist E, Birrer MJ, et al. Niraparib plus bevacizumab versus niraparib alone for platinum-sensitive recurrent ovarian cancer (NSGO-AVANOVA2/ENGOT-ov24): a randomised, phase 2, superiority trial. Lancet Oncol 2019;20:1409-19.

39 Konstantinopoulos PA, Waggoner SE, Vidal GA, et al. TOPACIO/ Keynote-162 (NCT02657889): a phase 1/2 study of niraparib + pembrolizumab in patients (pts) with advanced triple-negative breast cancer or recurrent ovarian cancer $(\mathrm{ROC})$ - results from ROC cohort. $J$ Clin Oncol 2018;36:106

40 Drew Y, de Jonge M, Hong SH, et al. An open-label, phase II basket study of olaparib and durvalumab (MEDIOLA): results in germline BRCA-mutated (gBRCA m) platinum-sensitive relapsed (PSR) ovarian cancer (OC). Gynecol Oncol 2018;149:246-7.

41 Staropoli N, Ciliberto D, Del Giudice T, et al. The era of PARP inhibitors in ovarian cancer: "class action" or not? A systematic review and meta-analysis. Crit Rev Oncol Hematol 2018;131:83-9.

42 Berek JS, Matulonis UA, Peen U, et al. Safety and dose modification for patients receiving niraparib. Ann Oncol 2018;29:1784-92.

43 Kaye SB, Lubinski J, Matulonis U, et al. Phase II, open-label, randomized, multicenter study comparing the efficacy and safety of olaparib, a poly (ADP-ribose) polymerase inhibitor, and pegylated liposomal doxorubicin in patients with BRCA1 or BRCA2 mutations and recurrent ovarian cancer. J Clin Oncol 2012;30:372-9. 
44 Audeh MW, Carmichael J, Penson RT, et al. Oral poly(ADP-ribose) polymerase inhibitor olaparib in patients with BRCA1 or BRCA2 mutations and recurrent ovarian cancer: a proof-of-concept trial. Lancet 2010;376:245-51.

45 Oza AM, Matulonis UA, Malander S, et al. Quality of life in patients with recurrent ovarian cancer treated with niraparib versus placebo (ENGOT-OV16/NOVA): results from a double-blind, phase 3, randomised controlled trial. Lancet Oncol 2018;19:1117-25.

46 National Comprehensive Cancer Network (NCCN). NCCN clinical practice guidelines in oncology. Cancer-related fatigue. Version 2, 2019. Available: https://www.nccn.org/professionals/physician_gls/ pdf/fatigue.pdf

47 Hopkins TA, Ainsworth WB, Ellis PA, et al. PARP1 trapping by PARP inhibitors drives cytotoxicity in both cancer cells and healthy bone marrow. Mol Cancer Res 2019;17:409-19.

48 National Comprehensive Cancer Network (NCCN). NCCN clinical practice guidelines in oncology. Hematopoietic growth factors. Version 1, 2019. Available: https://www.nccn.org/professionals/ physician_gls/pdf/growthfactors.pdf

49 Schiffer CA, Bohlke K, Delaney M, et al. Platelet transfusion for patients with cancer: American Society of Clinical Oncology clinical practice guideline update. J Clin Oncol 2018;36:283-99.

50 ZEJULATM (niraparib) capsules. European Medicine Agency (EMA) website. Available: https://www.ema.europa.eu/en/documents/ product-information/zejula-epar-product-information en.pdf [Accessed on 17 Mar 2020].

51 Davis CC, Caulfield S. Nausea and vomiting: managing side effects from PARP inhibitors. Oncology 2019;33:58-61.

52 National Comprehensive Cancer Network (NCCN). NCCN clinical practice guidelines in oncology. Antiemesis. Version 1, 2019. Available: https://www.nccn.org/professionals/physician_gls/pdf/ antiemesis.pdf

53 KYTRIL® (granisetron hydrochloride). U.S. Food and Drug Administration website. Available: https://www.accessdata fda.gov/drugsatfda_docs/label/2009/020239s021,020305s014, 021238s007lbl.pdf [Accessed on 23 Dec 2019].

54 Moayyedi P, Lacy BE, Andrews CN, et al. ACG and CAG clinical guideline: management of dyspepsia. Am J Gastroenterol 2017;112:988-1013.

55 Magnani C, Mastroianni C, Giannarelli D, et al. Oral hygiene care in patients with advanced disease: an essential measure to improve oral cavity conditions and symptom management. Am J Hosp Palliat Care 2019;36:815-9.

56 National Comprehensive Cancer Network (NCCN). NCCN clinical practice guidelines in oncology. Palliative care. Version 2, 2019 Available: https://www.nccn.org/professionals/physician_gls/pdf/ palliative.pdf

57 Zibetti Dal Molin G, Westin SN, Msaouel P, et al. Discrepancy in calculated and measured glomerular filtration rates in patients treated with PARP inhibitors. Int J Gynecol Cancer 2020;30.

58 Moore KN, Mirza MR, Matulonis UA. The poly (ADP ribose) polymerase inhibitor niraparib: management of toxicities. Gynecol Oncol 2018;149:214-20.
59 Zhao H, Sifakis EG, Sumida N, et al. PARP1- and CTCF-mediated interactions between active and repressed chromatin at the lamina promote oscillating transcription. Mol Cell 2015;59:984-97.

60 National Comprehensive Cancer Network (NCCN). NCCN clinical practice guidelines in oncology. Adult cancer pain. Version 3, 2019. Available: https://www.nccn.org/professionals/physician_gls/pdf/ pain.pdf

61 Ilnytska O, Lyzogubov VV, Stevens MJ, et al. Poly(ADP-ribose) polymerase inhibition alleviates experimental diabetic sensory neuropathy. Diabetes 2006;55:1686-94.

62 Ta LE, Schmelzer JD, Bieber AJ, et al. A novel and selective poly (ADP-ribose) polymerase inhibitor ameliorates chemotherapyinduced painful neuropathy. PLoS One 2013;8:e54161.

63 Balko R, Hurley R, Jatoi A. Poly (ADP-ribose) polymerase inhibition for chemotherapy-induced peripheral neuropathy: a meta-analysis of placebo-controlled trials. J Palliat Med 2019;22:977-80.

64 Ison G, Howie LJ, Amiri-Kordestani L, et al. FDA approval summary: niraparib for the maintenance treatment of patients with recurrent ovarian cancer in response to platinum-based chemotherapy. Clin Cancer Res 2018;24:4066-71.

65 Whelton PK, Carey RM, Aronow WS, et al. 2017 ACC/AHA/AAPA ABC/ACPM/AGS/APhA/ASH/ASPC/NMA/PCNA guideline for the prevention, detection, evaluation, and management of high blood pressure in adults: executive summary: a report of the American College of Cardiology/American Heart Association Task Force on clinical practice guidelines. Circulation 2018;138:e426-83.

66 Madariaga A, Lheureux S, Oza AM. Tailoring ovarian cancer treatment: implications of $B R C A 1 / 2$ mutations. Cancers 2019;11:E416

67 Schulz E, Valentin A, Ulz P, et al. Germline mutations in the DNA damage response genes BRCA1, BRCA2, BARD1 and TP53 in patients with therapy related myeloid neoplasms. J Med Genet 2012;49:422-8.

68 Friedlander M, Gebski V, Gibbs E, et al. Health-related quality of life and patient-centred outcomes with olaparib maintenance after chemotherapy in patients with platinum-sensitive, relapsed ovarian cancer and a BRCA1/2 mutation (SOLO2/ENGOT Ov-21): a placebo-controlled, phase 3 randomised trial. Lancet Oncol 2018;19:1126-34.

69 Bedel J, Lorusso D, Aghajanian C, et al. Patient-centered outcomes in ARIEL3, a phase 3, randomized, placebo-controlled study of rucaparib maintenance treatment in patients with recurrent ovarian carcinoma. ISPOR Annual Meeting 2019.

70 Guy H, Walder L, Fisher M. Cost-effectiveness of niraparib versus routine surveillance, olaparib and rucaparib for the maintenance treatment of patients with ovarian cancer in the United States. Pharmacoeconomics 2019;37:391-405

71 Wallace K, Goble S, Isaacson J, et al. Comment on: "Costeffectiveness of niraparib versus routine surveillance, olaparib and rucaparib for the maintenance treatment of patients with ovarian cancer in the United States". Pharmacoeconomics 2019;37:1065-7.

72 Ang JE, Gourley C, Powell CB, et al. Efficacy of chemotherapy in BRCA1/2 mutation carrier ovarian cancer in the setting of PARP inhibitor resistance: a multi-institutional study. Clin Cancer Res 2013:19:5485-93. 